\title{
Parallel ridge pattern on dermoscopy: observation in non-melanoma cases
}

\section{Padrão dermatoscópico em cristas paralelas: observação em casos não-melanoma}

\author{
Tainá Scalfoni Fracaroli ${ }^{1}$ \\ Juan Piñeiro Maceira ${ }^{2}$
}

\author{
Fernanda Guedes Lavorato ${ }^{1}$ \\ Carlos Barcaui ${ }^{3}$
}

\begin{abstract}
The acral melanoma is the most prevalent type of melanoma in the non-Caucasian population, and dermoscopy is a useful tool for earlier diagnosis and differentiation from benign lesions. The dermoscopic pattern often associated with melanoma on the volar skin is the parallel ridge, with $99 \%$ specificity according to the literature. However, this pattern can also occur in several benign acral lesions, so it is important to make a good interpretation of this pattern, along with the clinical history and evolution.
\end{abstract}

Keywords: Dermoscopy; Melanoma; Melanosis; Nevus pigmented

Resumo: O melanoma acral é o tipo mais prevalente de melanoma na população não caucasiana, sendo a dermatoscopia uma ferramenta útil para um diagnóstico mais precoce e diferenciação com lesões benignas. O padrão dermatoscópico, frequentemente, associado ao melanoma na pele volar é o de cristas paralelas, com 99\% de especificidade segundo a literatura. No entanto, também pode ocorrer em diversas lesões acrais benignas, por isso é importante uma boa interpretação deste padrão, associado a história clínica e evolução.

Palavras-chave: Dermatoscopia; Melanoma; Melanose; Nevo pigmentado

\section{INTRODUCTION}

It is estimated that acral lentiginous melanoma represents $10 \%$ of all cutaneous melanomas, being the most prevalent form of this tumor in the non-caucasian population and corresponding to half the cases of melanoma diagnosed among Japanese patients. Prognosis is generally bad due to the late diagnosis. ${ }^{1}$
Dermoscopy is useful to differentiate between acral melanomas and benign lesions. As according to the literature, the dermoscopic pattern of parallel ridges has $86 \%$ sensibility and $99 \%$ specificity to detect acral melanomas, and benign lesions often present the parallel furrow pattern. ${ }^{2,3,4}$

\footnotetext{
Received on 12.08.2012.

Approved by the Advisory Board and accepted for publication on 24.09.2012.

* Work performed at Pedro Ernesto University Hospital -Rio de Janeiro State University (HUPE-UERJ) - Rio de Janeiro (RJ), Brazil. Conflict of interest: None

Financial funding: None

MD - Dermatologist at Private Clinic - Rio de Janeiro (RJ), Brazil.

MD - Associated Professor at the Pathology Department at Rio de Janeiro Federal University (UFRJ) - Rio de Janeiro (RJ), Brazil.

MD - Associated Professor of Dermatology at Rio de Janeiro State University Medical School (UERJ) - Rio de Janeiro (RJ), Brazil.

(C2013 by Anais Brasileiros de Dermatologia
} 
The palmar-plantar region has a thick and compact stratum corneum, containing dermatoglyphs, formed by furrows and ridges. Histologically, the ridges correspond to the interpapillary pegs, also known as crista profunda intermedia where the eccrine glands ducts penetrate, and the furrows correspond to the crista profunda limitans, that do not relate to the eccrine ductal structures. ${ }^{5,6}$ The dermoscopic pattern of parallel ridges is described as an accentuated pigmentation in the deep intermediate ridges (crista profunda intermedia), which acquire the same aspects of parallel ridges seen on glabrous skin. ${ }^{3,5,7}$ According to the algorithm depicted by Saida, ${ }^{1}$ acquired melanocytic lesions that present a parallel ridge dermoscopy pattern should be biopsied. However, this pattern has been recently reported on various benign lesions. ${ }^{8,9,10}$

\section{DISCUSSION}

The images displayed on this article illustrate the pattern of parallel ridges in one case of racial melanosis and another case of congenital melanocytic nevus, phototypes $\mathrm{V}$ and IV respectively, without obliteration of the acrosyringia, which are the superficial openings of the eccrine glands on the epidermis (Figures 1, 2, 3 and 4). Some authors also found this same pattern in lesions for which, later histopathology examination did not confirm the clinical suspicion of acral melanoma, thus being labeled by them as "atypical acral melanosis".

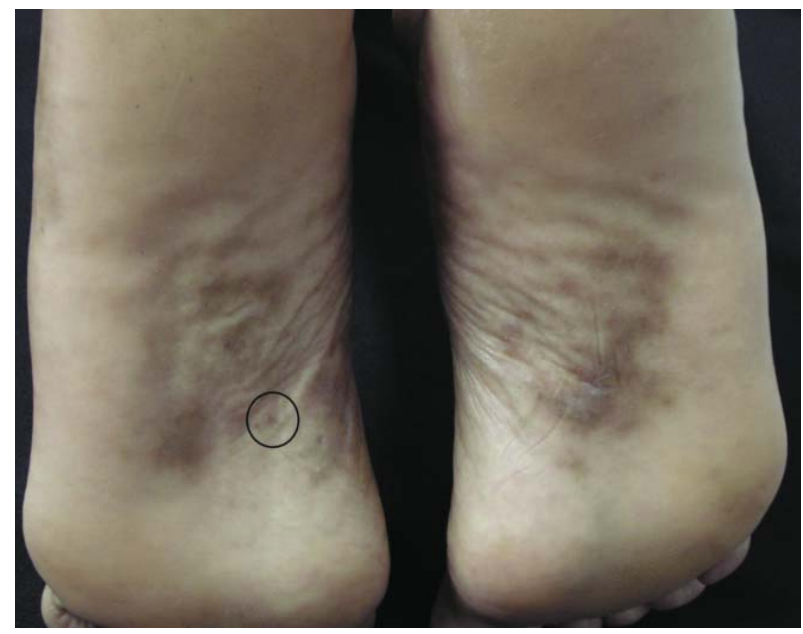

FIGURE 1: Racial melanosis on the plantar arch of a phototype $\mathrm{V}$ patient

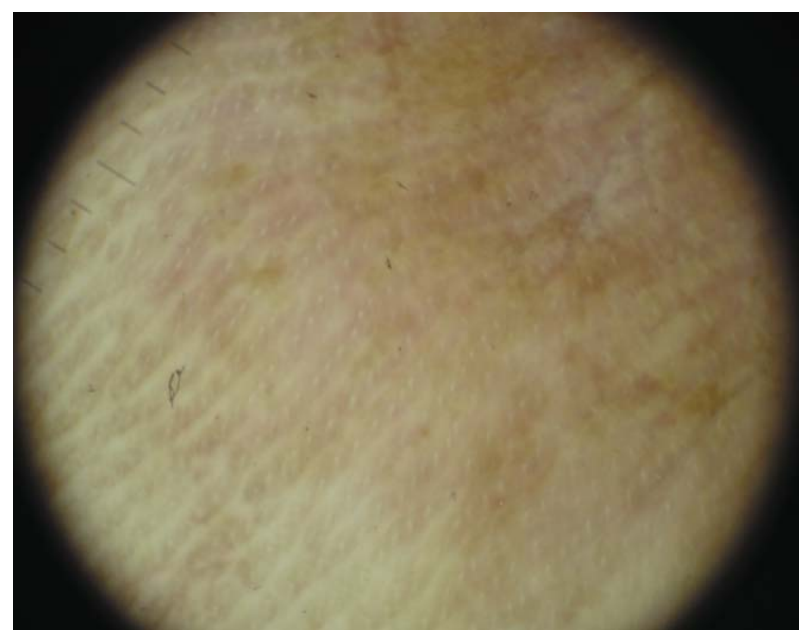

FIGURE 2: Dermoscopy showing parallel ridge pattern and mottled pigmentation area sparing the acrosyringia aperture

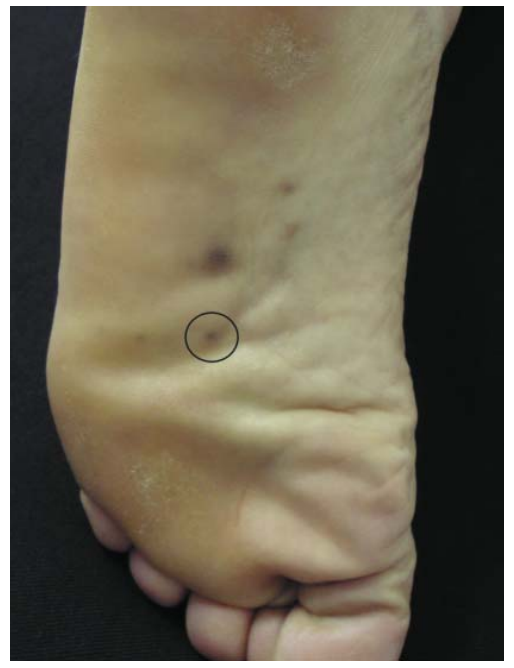

Figure 3: Melanocytic nevus on the plantar region of a phototype IV patient, that also presented with a congenital giant nevus on the torso )

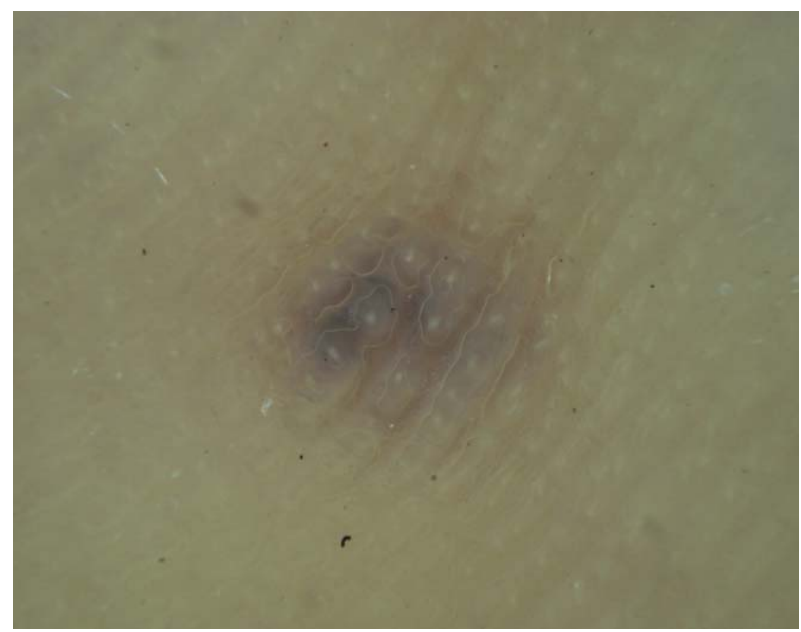

FIGURE 4: Parallel ridge dermoscopic pattern with preservation of the eccrine glands aperture and pigmentation on the furrows. 
In congenital acral nevi, blue homogeneous or parallel ridge patterns may be observed and Minagawa described a congenital nevus with atypical dermoscopic pattern: an uncircumscribed, mottled, brownish pigmentation. ${ }^{7}$ We disagree with the specificity attributed to the parallel ridge pattern for the dermoscopic diagnosis of acral melanoma, because we have increasingly observed benign acral lesions, such as lentiginosis, racial melanosis, melanocytic nevi, drug-induced hyperpigmentation, subcorneal hemorrhage and dye-related pigmentation, particularly in higher phototypes, presenting this same pattern. However, we recognize that on lentiginous acral melanoma, the melanocytic proliferation is disseminated and occupies the crista profunda intermedia, determining not only the ridge pigmentation, but also the obliteration of the eccrine gland ducts, a fact that must be considered for the differential diagnosis between benign and malign lesions. In the racial melanosis histopathology one can observe the disseminated increase of pigmentation at the dermoepidermal junction, without melanocytic proliferation;

\section{REFERENCES}

1. Saida $\mathrm{T}$, Koga $\mathrm{H}$, Uhara $\mathrm{H}$. Key points in dermoscopic differentiation between early acral melanoma and acral nevus. J Dermatol. 2011;38:25-34.

2. Saida T, Miyazaki A, Oguch S, Ishihara Y, Yamazaki Y, Murase S, et al. Significance of dermoscopic patterns in detecting malignant melanoma on acral volar skin: results of a multicenter study in Japan. Arch Dermatol. 2004;140:1233-8.

3. Saida T, Oguch S, Miyazaki A. Dermoscopy for acral-pigmented lesion. Clin Dermatol. 2002;20:279-85.

4. Rezze GG, Soares de Sá BC, Neves RI. Dermoscopy: the pattern analysis. An Bras Dermatol. 2006;81:261-8.

5. Miyazaki A, Saida T, Koga H, Oguchi S, Suzuki T, Tsuchida T. Anatomical and histopathological correlates of the dermoscopic patterns seen in melanocytic nevi on the sole: A retrospective study. J Am Acad Dermatol. 2005;53:230-6.

6. Ferreira CMM, Barcaui C, Maceira JP. Atlas de Dermatoscopia. Aplicação clínica e correlação histopatológica. Rio de Janeiro: Di Livros; 2011.

7. Minagawa A, Koga H, Saida T. Dermoscopic characteristics of congenital melanocytic nevi affecting acral volar skin. Arch Dermatol. 2011;147:809-13.

8. Tanioka M. Benign acral lesion showing parallel ridge pattern on dermoscopy. J Dermatol. 2011;38:41-4.

9. Kilinc Karaarslan I, Akalin T, Unal I, Ozdemir F. Atypical melanosis of the foot showing a dermoscopic feature of the parallel ridge pattern. J Dermatol. 2007;34:56-9.

10. Phan A, Dalle S, Marcilly MC, Bergues JP, Thomas L. Benign Dermoscopic Parallel Ridge Pattern Variants. Arch Dermatol. 2011;147:634. whilst in the congenital melanocytic nevi there are, generally, melanocytes occupying the papillary dermis and superficial rete dermis without injure to the acrosyringia, which corresponds to the parallel ridge aspect without the dermoscopic blurring of the eccrine ducts aperture.

Pigmented acral lesions often represent a diagnostic challenge, in which dermoscopy carries an important role as it allows the identification of specific patterns of benignancy or malignancy.

We, however, propose a critical analysis of the parallel ridge dermoscopic pattern, as we believe that, it cannot be evaluated separately. Being a peculiar anatomical site, much like the face, the involvement of the annexes, observed by the obliteration of the acrosyringia, is the sign that may suggest malignancy, besides other characteristics of the lesion and its own evolution. Further studies are necessary to better evaluate the specificity of parallel ridge pattern or to achieve a better definition, mainly in our country, where patients with higher phototypes represent the larger part of the population. $\square$

\author{
MAILING ADDRESS: \\ Tainá Scalfoni Fracaroli \\ Av. Vinte e oito de setembro, 77 - Vila Isabel \\ 20551-030 - Rio de Janeiro - RJ \\ Brazil \\ E-mail: tsfracaroli@yahoo.com.br
}

How to cite this article: Fracaroli TS, Lavorato FG, Maceira JP, Barcaui C. Parallel ridge pattern on dermoscopy: observation in non-melanoma cases. An Bras Dermatol. 2013;88(4):646-8. 